\title{
Balloon atrial septostomy under two dimensional echocardiographic control
}

\author{
LINDSEY D ALLAN, „ RANJIT LEANAGE, RAY WAINWRIGHT, MICHAEL C JOSEPH, \\ MICHAEL TYNAN
}

From the Department of Paediatric Cardiology, Guy's Hospital, London

SUMMARY Two dimensional echocardiography has been used to guide balloon atrial septostomy in five cases of transposition of the great arteries. A single lumen balloon catheter was used. The catheter can be accurately located within the left atrium before inflation of the balloon, thus avoiding some of the traumatic accidents possible during septostomy. The balloon can be observed creating the atrial defect and the approximate size of the resulting defect noted. It can also be seen if the foramen ovale is only being stretched and not torn. The use of the two dimensional echocardiogram during septostomy should significantly contribute to the speed, efficiency, and safety of the procedure.

Transposition of the great arteries is one of the most common cyanotic congenital heart diseases, affecting about one in 4000 live births. ${ }^{1}$ Before the introduction of surgical techniques to increase atrial mixing the mortality rate from transposition was high, $95 \%$ of cases dying by the end of the second year of life, approximately $40 \%$ of those in the first month. ${ }^{2}$ Surgical septectomy improved this situation vastly ${ }^{3}$ but there was still a very high mortality in the first three months of life. This led to the introduction of balloon septostomy. ${ }^{4}$ This palliative procedure allows the patient to survive until the appropriate time for corrective surgery. ${ }^{5}$ There is, however, a remaining small mortality which is directly attributable to technical failure of balloon atrial septostomy. The reasons for technical failure include failure to introduce the balloon catheter, ${ }^{6}$ failure of adequate septostomy, ${ }^{7}$ and traumatic damage caused by the balloon to structures other than the atrial septum. Atrial perforation and tricuspid valve perforation ${ }^{67}$ have both been reported. Failure of balloon atrial septostomy varies between seven in 43 in an early series ${ }^{6}$ to two in 44 in a more recent series. ${ }^{8}$ Some of this improvement in mortality is because traumatic damage to other structures has been avoided by careful positioning of the balloon before each "pull". The exact position of the balloon using $x$-ray screening alone is not always clear. The use of a double lumen balloon catheter allows chamber pressure to be recorded, thus eliminating the danger of inflating the balloon in a ^British Heart Foundation Junior Research Fellow.

Accepted for publication 28 August 1981 ventricular chamber. In addition, careful slow inflation of the balloon should ease the catheter out of a pulmonary vein or the left atrial appendage if it is wrongly positioned there.

Two dimensional echocardiography can be used to locate and position the balloon catheter. We have used this in five cases of transposition of the great arteries and feel this technique contributes significantly to the speed, efficiency, and safety of the septostomy procedure.

\section{Subjects and methods}

Five consecutive cases of suspected transposition of the great arteries were studied by two dimensional echocardiography. An Advanced Technical Laboratories Mark III Sector Scanner was used with a $5 \mathrm{MHz}$ transducer. The age range of the patients was from 1 day to 8 months (see Table). The diagnosis was confirmed by echocardiography in each case, being transposition and ventricular septal defect in four

Table Size of atrial septal defect created

\begin{tabular}{llll}
\hline Case No. & Age & Diagnosis & $\begin{array}{l}\text { Approximate size of } \\
\text { ASD created }(\mathrm{cm})\end{array}$ \\
\hline 1 & $2 \mathrm{wk}$ & TGA, VSD & 0.6 \\
2 & $2 \mathrm{~d}$ & TGA, VSD & 0.6 \\
3 & $8 \mathrm{mth}$ & TGA, VSD & None \\
4 & $1 \mathrm{~d}$ & TGA , VSD & 0.5 \\
5 & $2 \mathrm{~d}$ & TGA, VS \\
\hline
\end{tabular}

TGA, transposition of great arteries; VSD, ventricular septal defect; ASD, atrial septal defect. 
patients and transposition with intact septum in one. Cardiac catheterisation was performed and the haemodynamic assessment made. A single lumen Edwards Laboratories balloon septostomy catheter was introduced into the right saphenous vein. The echocardiograph transducer was positioned in the subcostal region to visualise the right atrial/inferior vena caval junction. The catheter was then advanced using screening until it was seen on the echocardiogram entering the right atrium. The atrial septum and foramen ovale were then identified echocardiographically and the catheter was passed through the foramen ovale to the left atrium under echocardiographic control without recourse to $x$-ray screening. The position of the balloon was confirmed by inflation with $0.5 \mathrm{ml}$ saline. The balloon was then fully inflated while being directly observed and then withdrawn across the atrial septum. The balloon could be monitored and recorded during each septostomy procedure (Fig. la and $b$ ). The approximate size of the defect created by the balloon during and at the end of the procedure could be estimated (Fig. 2a and b).

\section{Discussion}

The use of two dimensional echocardiography before catheterisation in a sick neonate greatly facilitates the catheterisation study. If a diagnosis of transposition of the great arteries is made it is only necessary to acquire confirmatory haemodynamic data at catheterisation and perform the balloon atrial septostomy as $\overrightarrow{\vec{F}}$ quickly as possible. This is particularly important ifo the infant's condition is poor. In our experience the음 use of the two dimensional echocardiogram during $\frac{\overline{\bar{s}}}{\bar{s}}$ catheterisation can further expedite the procedure.

The single lumen catheter is smaller than theo double lumen version and thus easier to introduce. ${ }^{\infty}$ One of the technical causes of failure may thereby be. avoided. The ability of the cross-sectional echocar- $\vec{\omega}$ diogram to identify accurately the position of the bal- $\stackrel{\omega}{\omega}$ loon within the heart means that the extra margin of safety provided by the double lumen catheter when:using $x$-ray screening alone is no longer required. The ${ }_{-}^{-2}$ position of the actual tip of the catheter is sometimesi difficult to determine. Once the catheter has adopted a curved course the echocardiographic plane may cut ${ }^{\supset}$ the catheter proximal to the tip, the tip itself being out ${ }_{c} \vec{c}$ of the plane of section. Partial inflation of the balloon, however, will always allow identification of the catheter tip. In addition, direct visualisation of the foramen $₹$ ovale or atrial septal defect facilitates the positioning $\vec{\bullet}$ and repositioning of the catheter in the left atrium, rendering the procedure simple and quick to perform. Our standard technique of between eight to 100 "pulls" was performed in each case without the need for $x$-ray screening during the procedure. In case 3 ito
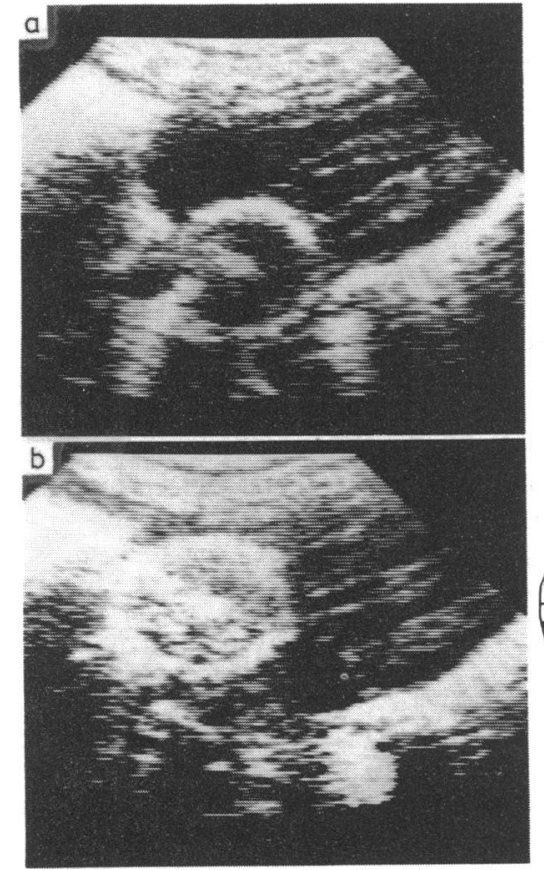

BEFORE SEPTOSTOMY
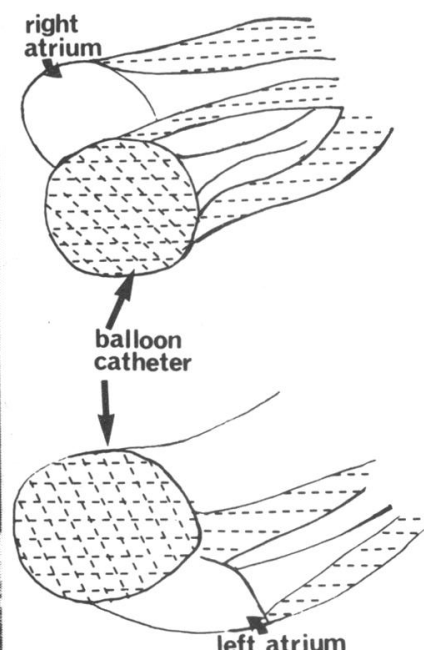

AFTER SEPTOSTOMY
Fig. 1 The subxiphoid four chamber section of the heart is visualised on the echocardiogram. (a) The inflated balloon catheter is seen within the left atrium before septostomy; (b) the balloon is seen within the right atrium after septostomy. 

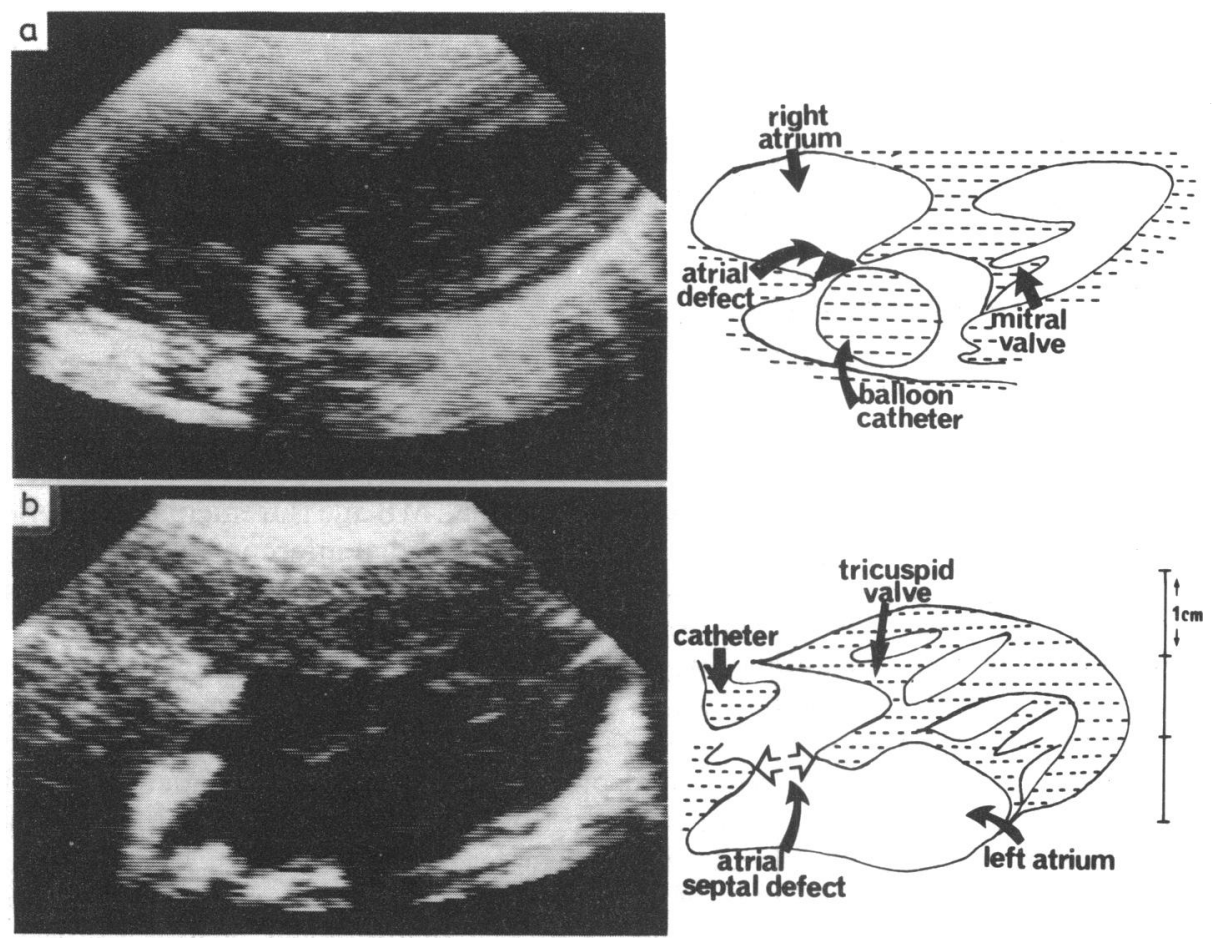

Fig. 2 (a) The balloon catheter, partially inflated, can be seen in the left atrium resting on the torn atrial septum; (b) the deflated balloon catheter is now in the right atrium after septostomy has been performed eight times. The approximate size of the defect can be measured.

appeared that the balloon was being compressed as it passed across the atrial septum and that no defect had been created.

A surgical septectomy was therefore performed in this patient. In cases $1,2,4$, and 5 the size of the defect created appeared to be approximately $0.5 \mathrm{~cm}$.

Using echocardiographic control it should be impossible to position the catheter incorrectly, and therefore injuries inflicted on withdrawal such as tricuspid valve damage or perforation of the left atrial-pulmonary vein junction may be completely avoided.

\section{References}

1 Keith JD, Rowe RD, Vlad P. Heart disease in infancy and childhood. 3rd ed. New York: McMillan Publishing, 1978.

2 Liebman P, Cullum L, Belloc NB. Natural history of transposition of the great arteries. Anatomy and birth and death characteristics. Circulation 1969; 40: 237-62.

3 Deverall PB, Tynan MJ, Carr I, et al. Palliative surgery in children with transposition of the great arteries. f Thorac Cardiovasc Surg 1969; 58; 721-9.
4 Rashkind WJ, Miller WM. Creation of an atrial septal defect without thoracotomy: a palliative approach to

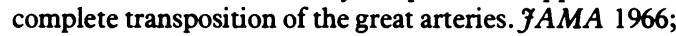
196: 991-2.

5 Tynan M. Survival of infants with transposition of great arteries after balloon atrial septostomy. Lancet 1971; i: 621-3.

6 Baker F, Baker L, Zoltun R, Zuberbuhler JR. Effectiveness of the Rashkind procedure in transposition of the great arteries in infants. Circulation 1971; 43, suppl 1: $1-6$.

7 Venables AW. Balloon atrial septostomy in complete transposition of great arteries in infancy. Br Heart $\mathcal{F}$ 1970; 32: 61-5.

8 Kratz C, Davignon A, Chartrand C, Stanley P. Simple 'd-transposition of the great arteries. Results of early balloon septostomy followed by two-stage surgical correction. F Thorac Cardiovasc Surg 1977; 73: 707-11.

Requests for reprints to Dr Lindsey D Allan, Guy's Hospital, London SE1 9RT. 